\title{
Studies on the Chemical Syntheses and on the Characteristics of Polyaniline Derivatives
}

\author{
L. H. C. MATTOSO, ${ }^{1 *}$ S. K. MANOHAR, ${ }^{2}$ A. G. MACDIARMID, ${ }^{2}$ and A. J. EPSTEIN ${ }^{3}$ \\ 'Instituto de Física e Química de São Carlos, USP-DFCM, C.P. 369, São Carlos, 13560-970, SP, Brazil, \\ ${ }^{2}$ University of Pennsylvania, Department of Chemistry, Philadelphia, Pennsylvania, \\ ${ }^{3}$ The Ohio State University, Departments of Chemistry and Physics, Columbus, Ohio
}

\begin{abstract}
SYNOPSIS
Syntheses of parent polyaniline and methyl, methoxy, and ethoxy ortho-substituted polyanilines were performed using the conventional chemical methodology and monitored using the new open-circuit-potential ( $V_{\alpha c}$ ) profile technique. The intermediate pernigraniline oxidation state was identified and isolated at the $V_{\text {oc }}$ maximum $(A)$ during the conventional chemical synthesis of poly(o-methoxyaniline) in the emeraldine oxidation state. The introduction of the substituent on the aniline ring leads to longer polymerization times and lower $V_{\text {oc }}$ values. Syntheses in the presence of two different monomers in solution were also investigated and showed preferential polymerization of the monomer with the lowest $V_{o c}$ potential. All polymers produced were characterized by elemental analysis, gel permeation chromatography, UV-VIS spectroscopy, and cyclic voltammetry. The influence of the substituent on the $V_{\text {oc }}$ profile and on the polymer characteristics are rationalized in terms of steric and electronic effects. (C) 1995 John Wiley \& Sons, Inc.
\end{abstract}

Keywords: polyanilines • derivatives $\bullet$ chemical synthesis • oxidation state

\section{INTRODUCTION}

Polyanilines form a class of polymers whose base forms have the general composition: $\left(-\mathrm{C}_{6} \mathrm{H}_{4}-\right.$ $\left.\mathrm{NH}-\mathrm{C}_{6} \mathrm{H}_{4}-\mathrm{NH}-\mathrm{C}_{6} \mathrm{H}_{4} \mathrm{~N}=\mathrm{C}_{6} \mathrm{H}_{4}=\mathrm{N}\right)_{n}$. They may exist in various oxidation states, from the completely reduced polymer, leucoemeraldine (containing only amine nitrogen atoms), to the completely oxidized polymer, pernigraniline (containing only imine nitrogen atoms). ${ }^{1}$ The half-oxidized polymer, named emeraldine, has been the most extensively studied since in addition to being very stable its doped state is the most conductive. This emeraldine state can also be easily obtained using classical oxidative chemical synthesis., ${ }^{2,3}$ Syntheses with aniline monomers have been studied for a long time,${ }^{4-6}$ but it was only recently ${ }^{3}$ that a good chemical elemental analysis consistent with a pure linear polymer was finally obtained. This polymer was

* To whom all correspondence should be addressed.

Journal of Polymer Science: Part A: Polymer Chemistry, Vol. 33, 1227-1234 (1995) (C) 1995 John Wiley \& Sons, Inc. synthesized in the presence of excess monomer and possessed high solubility in organic solvents which allowed its processing in the form of flexible fibers and films. ${ }^{3,7}$

The pernigraniline oxidation state has been shown to be an intermediate during the conventional chemical synthesis of parent polyaniline in the emeraldine oxidation state. ${ }^{8,9}$ This was detected by a novel potential profile technique which allowed the entire polymerization reaction to be monitored. Several studies have been reported on the synthesis of polyaniline and have focussed on the role played by dimers during the initiation stage, ${ }^{10}$ on the mechanisms of polymerization ${ }^{11-13}$ or on proposing routes of homopolymerization ${ }^{14}$ and copolymerization. ${ }^{15,16}$ However, the effect of substituents on the chemical synthesis and the use of the potential profile technique for polyaniline derivatives has not yet been investigated. It is well known that monitoring the synthesis is essential not only for the identification of intermediate products but also for helping polymer scientists to propose new routes of copolymer synthesis. ${ }^{17}$ 
This work was carried out in an attempt to shed more light on some aspects of the chemical synthesis of polyaniline derivatives, for which the potential profile technique was used. The effect of the aniline substituent on the syntheses which contained one and two monomers in the reaction mixture and on the characteristics of the polymers produced are rationalized in terms of steric and electronic effects.

\section{EXPERIMENTAL}

\section{Chemical Syntheses}

The syntheses of parent polyaniline, poly $(o$-methylaniline), poly(o-methoxyaniline), and poly(oethoxyaniline) were performed using the conventional chemical method ${ }^{3}$ at $0^{\circ} \mathrm{C}$ using ammonium peroxydisulfate in $1.0 M \mathrm{HCl}$. The ratio of monomer to oxidant was $4: 1$. Syntheses containing two different monomers in the reaction mixture, i.e., aniline and $o$-methylaniline in the respective ratios $90: 10$; $95: 5$, and $98: 2$ (volume percentage) were also performed. The procedure adopted was identical to that indicated above. All syntheses were monitored by the open circuit potential profile technique $\left(V_{\text {oc }}\right)^{9,18}$ using a calomel saturated electrode (SCE), and were terminated when the $V_{\text {oc }}$ value was observed to be practically constant $\left(V_{\text {oc }}\right.$ of $\sim 0.43,0.37,0.34$ and $0.32 \mathrm{~V}$ vs. SCE, respectively, for the $\mathrm{H}, \mathrm{CH}_{3}, \mathrm{OCH}_{3}$, and $\mathrm{OC}_{2} \mathrm{H}_{5}$ ortho-substituted polyanilines). The polymers obtained were all deprotonated in $0.1 \mathrm{M}$ ammonium hydroxide for $24 \mathrm{~h}$ and dried under dynamic vacuum prior to analysis.

The procedure to isolate the intermediate produced during the chemical synthesis of poly(omethoxyaniline) was analogous to that reported in the literature for parent polyaniline ${ }^{8,9}$ The synthesis was initiated in a similar manner to that described above. However, when an open circuit potential of $0.59 \mathrm{~V}$ was reached [point $\mathrm{A}$ in Fig. 1(c)], which occurred after approximately $20 \mathrm{~min}$, the reaction was interrupted by quenching the polymerization solution in a solution containing $0.1 \mathrm{M} \mathrm{NaOH}$ at $0^{\circ} \mathrm{C}$. The neutralized solution was then filtered in a Buchner funnel and extensively washed with several portions of distilled water and acetonitrile consecutively, until a colorless filtrate was obtained. The unstable powdery product (presumably in the pernigraniline oxidation state $)^{19}$ was immediately recovered in a vial and then dried in a vacuum line for $72 \mathrm{~h}$ at room temperature prior to analysis.

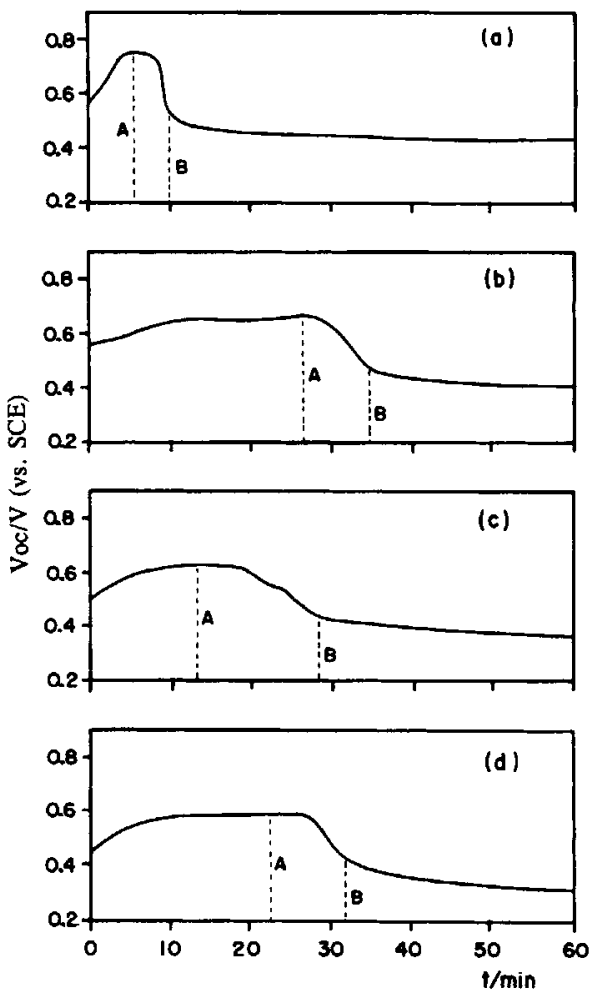

Figure 1. Open circuit potential ( $V_{\text {oc }}$ ) profile versus polymerization time $(t)$ for the chemical synthesis of: (a) polyaniline, (b) poly(o-methylaniline), (c) poly(o-methoxyaniline), and (d) poly(o-ethoxyaniline).

\section{Analyses}

The polymers in the base (deprotonated) form were further dried for $48 \mathrm{~h}$ before being submitted to carbon, hydrogen, and nitrogen analyses in a PerkinElmer model 240 elemental analyzer. Molecular weight determinations were performed using an ID Ultrastyragel linear gel permeation chromatography column (Waters/Millipore Co.) and a solvent mixture of $0.5 \% \mathrm{LiCl} / \mathrm{NMP}$ (weight/volume) as the mobile phase (see Ref. 20 for details). Monodisperse polystyrenes with molecular weights ranging from 3250 to $2,950,000$ were used as standards. The UVVIS absorption spectra were obtained from the polymers dissolved in $N$-methyl-2-pyrrolidinone (NMP) using a Perkin-Elmer model Lambda-9 Spectrophotometer. The FT-IR spectra of the polymers in the base powdery form (compressed $\mathrm{KBr}$ pellets) were obtained in the transmission mode with a Perkin-Elmer model 1760 Spectrometer. The electrochemical response of the polymer was measured by cyclic voltammetry in a PAR model 173 Potentiostat and a PAR model 175 Universal Programmer using a standard three-electrode cell and 
Table I. Elemental Analysis of Polyaniline and Its Derivatives in the Emeraldine Base Form

\begin{tabular}{clllllr}
\hline Substituent & & $\mathrm{C}$ & $\mathrm{H}$ & $\% \mathrm{~N}$ & $\mathrm{O}$ & $\begin{array}{r}\text { Total } \\
(\%)\end{array}$ \\
\hline \multirow{2}{*}{$\mathrm{H}$} & & $(\%)$ & $(\%)$ & $\begin{array}{c}\text { (\%) } \\
(\%)\end{array}$ & - & 100.00 \\
& Calcd: & 79.53 & 5.01 & 15.46 & - & 99.04 \\
$\mathrm{CH}_{3}$ & Found: & 78.82 & 4.94 & 15.28 & - & 100.00 \\
& Calcd: & 80.38 & 6.22 & 13.40 & - & 99.66 \\
$\mathrm{OCH}_{3}$ & Found: & 80.12 & 6.27 & 13.27 & - & 100.00 \\
& Calcd: & 69.1 & 5.39 & 11.62 & 13.28 & 99.22 \\
$\mathrm{OC}_{2} \mathrm{H}_{5}$ & Found: & 69.44 & 5.34 & 11.16 & $13.28^{\mathrm{a}}$ & 100.00 \\
& Calcd: & 71.37 & 6.32 & 10.41 & 11.90 & 99.67 \\
& Found: & 70.84 & 6.34 & 10.59 & $11.90^{\mathrm{a}}$ & \\
\hline
\end{tabular}

abtained from calculated values.

a saturated calomel electrode (SCE) as reference. The polymer was placed on the platinum working electrode with a glass filter paper as described elsewhere. $^{21}$

\section{RESULTS}

The open circuit potential profile $\left(V_{o c}\right)$ characteristic of the chemical synthesis of each polyaniline derivative is given in Figure 1. All curves present the same general shape, i.e., an increase in potential in the first stages of polymerization up to a maximum $\left[V_{\text {oc }}(A)\right]$, followed by a rapid decay at $t(B)$ and then a plateau at a final potential $\left(V_{o c_{\text {end }}}\right)$. The time for polymerization completion is named $t_{\text {end }}$ and varies between 1.5 and $2.5 \mathrm{~h}$. Upon derivatization, the $V_{\text {oc }}$ values [e.g., $V_{\text {oc }}(A)$ and $V_{\text {oc end }}$ ) decreased, whereas the times $t(A), t(B)$, and $t_{\text {end }}$ increased (see Fig. 1). The products obtained were characterized by elemental analysis, GPC, UV-VIS, and cyclic voltammetry. The amount of carbon, hydrogen, and nitrogen in the polymers synthesized (Table I) was over $99 \%$ in all cases. This is consistent with a pure polymer in the emeraldine oxidation state, as demonstrated by the comparison with the calculated

Table II. Molecular Weights $(\mathrm{g} / \mathrm{mol})$ of Chemically Synthesized Polyaniline and Its Derivatives

\begin{tabular}{lccc}
\hline Substituent & $M_{w}$ & $M_{n}$ & $M_{w} / M_{n}$ \\
\hline $\mathrm{H}$ & 53,000 & 25,000 & 2.08 \\
$\mathrm{CH}_{3}$ & 47,600 & 21,900 & 2.17 \\
$\mathrm{OCH}_{3}$ & 28,100 & 10,900 & 2.58 \\
$\mathrm{OC}_{2} \mathrm{H}_{5}$ & 41,400 & 18,000 & 2.30 \\
\hline
\end{tabular}

values. The molecular weight data in Table II show that the average molecular weight decreases and the polydispersivity increases upon derivatization of polyaniline.

The electrochemical response of these polymers was analysed by cyclic voltammetry in $1.0 \mathrm{M} \mathrm{HCl}$ (see Fig. 2). Two redox couples are seen for all derivatives similar to that observed for the parent polyaniline. ${ }^{21}$ The potential of the peak maximum

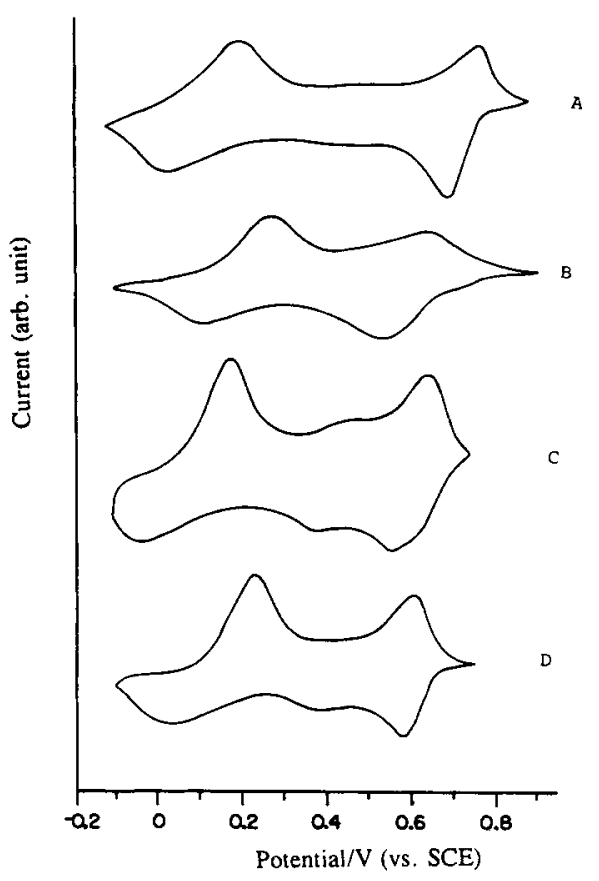

Figure 2. Cyclic voltammograms (current-I versus potential-E) performed in aqueous $1.0 \mathrm{M} \mathrm{HCl}$ of: (a) polyaniline, (b) poly(o-methylaniline), (c) poly(o-methoxyaniline), and (d) poly (o-ethoxyaniline); sweep rate $=50$ $\mathrm{mV} / \mathrm{s}$, first cycle. 
Table III. UV-VIS Absorption (in NMP Solution) and Cyclic Voltammetry $(1.0 \mathrm{M} \mathrm{HCl}, 50 \mathrm{mV} / \mathrm{s})$ Data of Polyaniline and Its Derivatives

\begin{tabular}{lllll}
\hline Substituent & $\lambda 1_{\max }(E)^{\mathrm{a}}$ & $\lambda 2_{\max }(E)^{\mathrm{a}}$ & $E 1_{1 / 2}^{\mathrm{b}}$ & $E 2_{1 / 2}^{\mathrm{b}}$ \\
\hline $\mathrm{H}$ & $327(3.79)$ & $635(1.95)$ & 0.14 & 0.72 \\
$\mathrm{CH}_{3}$ & $316(3.92)$ & $608(2.04)$ & 0.19 & 0.58 \\
$\mathrm{OCH}_{3}$ & $316(3.92)$ & $620(2.00)$ & 0.11 & 0.63 \\
$\mathrm{OC}_{2} \mathrm{H}_{6}$ & $313(3.96)$ & $615(2.02)$ & 0.14 & 0.61 \\
$90 / 10^{\mathrm{c}}$ & $323(3.83)$ & $616(2.01)$ & 0.18 & 0.59 \\
\hline
\end{tabular}

${ }^{a} \lambda_{\max }$ given in $\mathrm{nm}$ and energy $(E)$ given in $\mathrm{eV}$.

${ }^{\mathrm{b}} E_{1 / 2}$ given in volts vs. SCE.

' Sample ANI/METHYLANI $=90 / 10$.

changes depending on the bulkiness and electron density of the substituent, as will be discussed later. Table III shows that upon derivatization the halfpotential $\left(E_{1 / 2}\right)$ (for the peak at the highest potential) decreases, as does $\lambda_{\max }$ in the UV-VIS absorption spectra when compared to parent polyaniline. ${ }^{22}$

To identify the nature of the intermediate produced at the $V_{\text {oc }}$ maximum, during the chemical synthesis of polyaniline derivatives, the synthesis of poly (o-methoxyaniline) (POMA) was interrupted at a $V_{\text {oc }}$ value of $0.59 \mathrm{~V}$ [ point A in Fig. $1(\mathrm{c})$ ] . The product was isolated as described in the previous section and characterized by elemental analysis, UVVIS, and FT-IR spectroscopies. The results obtained show that the polymer was in the fully oxidized state. This was indicated by the reduced percentage of hydrogen in the product [ found (calculated): $\mathrm{C}=67.36 \%(70.00 \%), \mathrm{H}=4.85 \%(5.00 \%), \mathrm{N}$ $=10.92 \%(11.67 \%)]$, when compared to the value given in Table I for this polymer in the emeraldine oxidation state. Furthermore, changes in the UVVIS and FT-IR spectra were similar to those seen for parent polyaniline as it goes from the emeraldine
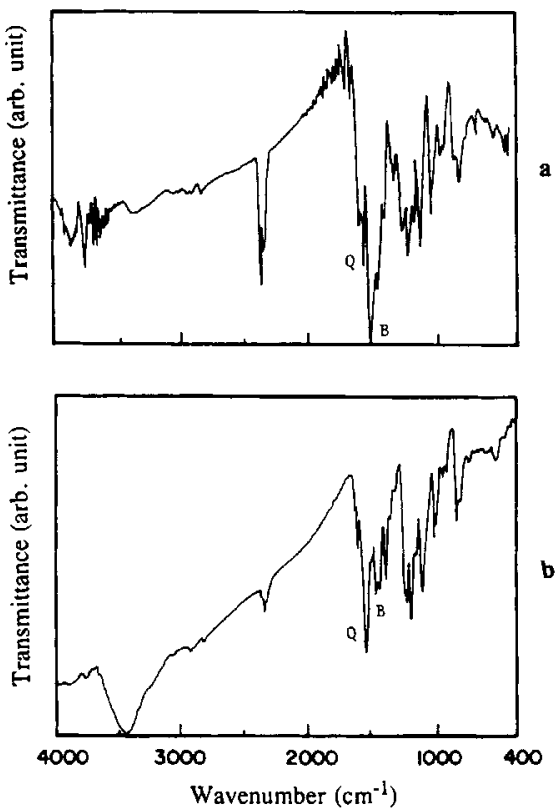

Figure 3. FT-infrared spectra of poly(o-methoxyaniline) chemically synthesized in the following oxidation state: (a) emeraldine base and (b) pernigraniline base; point $B$ and $Q$ are assigned, respectively, to benzoid and quinoid structures.

to the pernigraniline oxidation state. ${ }^{22}$ The UV-VIS spectra of pernigraniline for poly ( $o$-methoxyaniline) displayed a shift in $\lambda_{\max }$ of the excitonic transition to lower values (from 620 to $565 \mathrm{~nm}$ ) when compared to emeraldine. This change of oxidation state was also apparent in the FT-IR analysis shown in Figure 3 , where an increase in the relative intensity ratio of quinoid $\left(1595 \mathrm{~cm}^{-1}\right)$ to benzoid $\left(1502 \mathrm{~cm}^{-1}\right)$ structures occurred, as expected.

As shown in Figure 4, the $V_{\text {oc }}$ curve for the synthesis containing a mixture of aniline and $o$-methylaniline monomers is quite different from those ob-

Table IV. Open Circuit Potential Profile Data of the Syntheses from Solutions Containing a Mixture of Aniline and $o$-Methylaniline at Different Ratios (ANI/METHYLANI)

\begin{tabular}{cccccc}
\hline ANI/METHYLANI & $V_{\text {oc }}(A)^{\mathrm{a}}$ & $t(A)^{\mathrm{b}}$ & $t(B)^{\mathrm{b}}$ & $t_{\text {end }} \mathrm{b}^{\mathrm{b}}$ & Yield (\%) \\
$0 / 100$ & 0.67 & 0.45 & 0.58 & 2.0 & 67 \\
$90 / 10$ & 0.71 & 1.50 & 2.00 & 4.5 & 7 \\
$95 / 5$ & 0.71 & 1.15 & 1.60 & 4.0 & 3 \\
$98 / 2$ & 0.74 & 0.26 & 0.42 & 3.0 & $<1$ \\
$100 / 0$ & 0.75 & 0.11 & 0.21 & 1.5 & 72 \\
\hline
\end{tabular}

${ }^{a} V_{\mathrm{oc}}(A)=$ maximum open circuit potential (volts vs. SCE), i.e., point A in Figure 1

${ }^{\mathrm{b}} t(A)=$ time required to reach $V_{o c}(A), t(B)=$ time required to reach $V_{o c}(B), t_{\text {end }}=$ total polymerization time (times given in minutes). 




Figure 4. Open circuit potential $\left(V_{o c}\right)$ profile versus polymerization time $(t)$ for the chemical synthesis from a mixed solution of aniline and 0 -methylaniline in the following ratios (ANI/METHYLANI): (a) 95/5, (b) 90/10.

tained for the synthesis from the solutions containing only one type of monomer. The maximum in $V_{\text {oc }}$ appears as a long plateau, which decays only after more than $1.5 \mathrm{~h}$, when for example concentrations as low as $5 \%$ of $o$-methylaniline are used. Table IV summarizes the main data obtained from these syntheses. The addition of a small amount of $o$ methylaniline increases remarkably the times $t(A)$, $t(B)$, and $t_{\text {end }}$. Furthermore, the polymerization yield is consistent with the amount of $o$-methylaniline monomer added. The yields for polyanilines usually range from 50 to $70 \%,{ }^{23}$ as we have also observed in this study.

The products of the syntheses from solutions containing a mixture of aniline and $o$-methylaniline (ANI/METHYLANI) were characterized by elemental analysis, GPC, UV-VIS spectroscopy and cyclic voltammetry. The carbon to nitrogen ratio (C/N) for the sample ANI/METHYLANI 90/10 $(\mathrm{C}=79.84 \%, \mathrm{H}=5.96 \%, \mathrm{~N}=13.14 \%, \mathrm{C} / \mathrm{N}=6.1)$ is identical, within experimental error, to that calculated for the poly ( $o$-methylaniline) in the emeraldine base form $(\mathrm{C} / \mathrm{N}=6.0)$. For the parent polyaniline this ratio would be $\mathrm{C} / \mathrm{N}=5.1$. Figure 5 shows the cyclic voltammograms of the ANI/METHYLANI $90 / 10$ which is basically the same as that of the poly (o-methyaniline) homopolymer, as confirmed by the $E_{1 / 2}$ values in Table III. Furthermore, the $\lambda_{\max }$ of the excitonic transition in the UV-VIS electronic spectrum of this sample $(616 \mathrm{~nm})$ is closer to that of poly (o-methylaniline) $(608 \mathrm{~nm})$ than to the parent polyaniline $(635 \mathrm{~nm})$.

\section{DISCUSSION}

\section{Studies on the Chemical Synthesis}

The $V_{o c}$ curve of polyaniline derivatives presented basically the same pattern as the parent polymer, ${ }^{8}$ i.e., a $V_{o c}$ maximum during the first stages of polymerization followed by a plateau in the final stages. In the chemical synthesis of parent polyaniline ${ }^{9}$ it has been observed that the polymer is essentially formed at $V_{\mathrm{oc}}(B)$ (indicated in Fig. 1). Furthermore, at the value of $V_{\text {oc }}(A)$ an intermediate (pernigraniline) was identified for parent polyaniline. Similarly, for poly ( $O$-methoxyaniline) the equivalent intermediate was also identified and isolated at $V_{\text {oc }}(A)$ during the conventional chemical synthesis of the polymer in the emeraldine state. The identification and isolation of the polymer in the pernigraniline state can also be made by electrochemical means, as described elsewhere. ${ }^{15}$

The $V_{\mathrm{oc}}$ monitoring of the chemical synthesis showed that the presence of the substituent at the ortho-position of the aniline ring leads to longer times $t(A), t(B)$, and $t_{\text {end }}$ due to steric effects. The steric hindrance for coupling increases when the substituent is bulkier. However, electronic effects from the substituent also play an important role. The monomer reactivity increases with increasing electron donating ability of the substituent. This facilitates the coupling reaction during polymerization and may compensate for the volume increase, as appears to be the case for poly ( $o$-methoxyaniline) which polymerizes faster than poly(o-methylaniline).

It was also observed that the potential value at $V_{\text {oc }}(A)$ (as well as at $V_{\text {oc }}$ ) decreased upon derivatization. The decrease was larger for bulkier and more electron donating substituents. The ease of protonation is given by the aniline basicity ${ }^{24}$ which obeys the same order as that observed for the $V_{o c}$, i.e., $\mathrm{OC}_{2} \mathrm{H}_{5}>\mathrm{OCH}_{3}>\mathrm{CH}_{3}>\mathrm{H}$. Protonation is the first step of the oxidative polymerization of these anilines ${ }^{14}$ and, therefore, may be correlated to the oxidation potential $V_{\mathrm{oc}}(A)$. This same trend is also seen in the electropolymerization of these mono- 




Figure 5. Cyclic voltammograms in aqueous $1.0 \mathrm{M} \mathrm{HCl}$ of the sample $90 / 10$ (ANI/ METHYLANI); sweep rate $=50 \mathrm{mV} / \mathrm{s}$, first cycle.

mers, ${ }^{25}$ where a decrease in the monomer oxidation potential occurs in the same order as above.

The results presented so far suggest that two factors might contribute significantly to the oxidative polymerization of polyanilines and its derivatives: (i) a thermodynamic factor associated with the intermediate in the pernigraniline oxidation state at $V_{\text {oc }}(A)$; and (ii) a kinetic factor associated with the times $t(B)$ (of propagation) and $t_{\text {end }}$ (of total polymerization ).

The study of the syntheses from mixed monomer solutions elucidates the relationship between these factors. The $V_{o c}$ curves for these syntheses are quite different from those obtained for both pure homopolymers. The properties of the final product, however, are very similar to those of the poly ( $o$-methylaniline) homopolymer. Interestingly, the polymerization of $o$-methylaniline (presented in a much smaller quantity) also inhibited the subsequent polymerization of aniline. This indicates a preferential polymerization of the monomer whose reaction is thermodynamically more favorable [lower $V_{\mathrm{oc}}(A)$ potential for the pernigraniline intermediate], although the polymerization is slower due to the effect of steric hindrance for coupling.

The longer times for $t(A), t(B)$, and $t_{\text {end }}$, as well as differences between the characteristics for ANI/ METHYLANI and pure $o$-methylaniline may be explained in terms of the relative reagent ratios. In the case of the conventional synthesis of poly ( $O$ methylaniline), the oxidant : monomer : $\mathrm{HCl}$ molar ratio is $1.0: 4.0: 9.9$. On the other hand, for ANI/
METHYLANI syntheses this ratio is different due to preferential polymerization. Considering that only the $o$-methylaniline monomer fraction is reacting, then the reactants ratio is $1.0: 4 / 10: 9.9$ (in the case of ANI/METHYLANI 90/10). It is likely that the very dilute $o$-methylaniline in solution is preferentially polymerized by the oxidant, the reaction being limited by the low concentration of this monomer. After the $o$-methylaniline is all consumed, the remaining oxidant may reoxidize the poly ( $O$ methylaniline) already formed (this may possibly lead to a somewhat more oxidized polymeric structure), but does not promote the polymerization of the parent aniline monomer. It has been demonstrated from electrochemical studies ${ }^{26}$ that the oxidation potential of aniline-based polymers is lower than that of its respective monomers. This corroborates the finding that poly (o-methylaniline) is preferentially oxidized when compared with the parent aniline monomer, whose polymerization is therefore inhibited. These results may be of importance for investigating copolymerization routes of aniline monomers on the basis of preferential polymerization.

\section{Characteristics of Polyaniline Derivatives}

The characterization of polyaniline derivatives, presented in the Results section, shows unequivocally that the polymers are in the emeraldine oxidation state. ${ }^{3,21,22}$ Henceforth, we focus on the influ- 
ence that the substituent has on the characteristics of these polymers.

The UV-VIS data in Table III for polyaniline derivatives in the base form indicate two $\lambda_{\max }$ peaks at $\sim 4$ and $\sim 2 \mathrm{eV}$, assigned respectively to the $\pi-$ $\pi^{*}$ transition and to the formation of a molecular exciton localized in the three nitrogen..$^{22}$ An increase in the energy of the excitonic transition is observed upon derivatization because the interchain separation is increased. This has been confirmed by $x$-ray measurements on poly (o-methylaniline), ${ }^{27}$ which presented an interchain distance $5 \%$ longer than that of the parent polymer. As a consequence, the interchain mobility of charge (and/or spin) is reduced. Moreover, derivatization can also hamper intrachain transport by forcing the adjacent aromatic rings out of planarity because of unfavorable steric interactions. ${ }^{28}$ This would tend to decrease the conjugation along the polymer backbone (reducing the intrachain conductivity contribution), and would increase the resonance energy of the emeraldine oxidation state. Consistent with this, the energy of the excitonic transition is closely related to the electronic conductivity of polyanilines. ${ }^{22}$

The electronic effect of the substituent also influences the transition energy. By increasing the electron density of the rings, the electron donating ability of the alkoxy substituent favors electron delocalization on the polymer backbone. This promotes a decrease in the energy of the excitonic transition of poly(o-alkoxyaniline)s which present a lower transition energy than poly (o-methylaniline).

It is important to stress that the cyclic voltammetry results confirm the analysis of the $V_{\text {oc }}$ potential profile presented above. It is known ${ }^{21}$ that the second redox couple, which appears at a more positive potential in cyclic voltammograms, is assigned to the polymer in the pernigraniline oxidation state. For the substituted polyanilines this redox couple occurs at lower values than for the parent polymer, ${ }^{21}$ which closely agrees with the $V_{\text {oc }}(A)$ values measured during the chemical synthesis. Thus, it is easier to oxidize the substituted polyanilines to the pernigraniline oxidation state, than it is for the parent polyaniline. Furthermore, the potential difference between the two redox couples is smaller than for the parent polymer. Derivatization of polyaniline seems to induce destabilization of the polymer in the emeraldine oxidation state, which is consequently stable within a shorter potential range. Indeed, substituted polyanilines have been shown to be less stable ${ }^{29}$ than polyaniline, and more susceptible to degradation upon doping in acidic solution. ${ }^{30}$
The average molecular weights and polydispersivity of the polyaniline derivatives seem to be particularly affected by steric effects of the substituent. The increased hindrance to coupling during polymerization, introduced by the substituent, hampers the backbone chain growth. This decreases the molecular weight and also leads to a more polydisperse polymer.

\section{CONCLUSIONS}

The open circuit potential profile technique has been shown to be a valuable tool for monitoring the chemical synthesis of polyaniline and its derivatives. It enabled the detection and isolation of an intermediate (pernigraniline oxidation state) during the conventional chemical synthesis of polyaniline derivatives in the emeraldine oxidation state. When there are two different types of monomer in solution, polymerization was observed to occur preferentially for the polymer with the lower value of $V_{\text {oc }}$ maximum. The influence of the substituent on the chemical synthesis profile and on the characteristics of the polyanilines produced can be rationalized in terms of steric and electronic effects.

The financial support given by CNPq and FAPESP (Brazil) and also by the National Science Foundation MRL program, under the Grant No. DMR 91-20668 is gratefully acknowledged.

\section{REFERENCES AND NOTES}

1. A. G. MacDiarmid and A. J. Epstein, Makromol. Chem. Macromol. Symp., 51, 11 (1991).

2. E. M. Genies, A. Boyle, M. Lapkowski, and C. Tsintavis, Synth. Met., 36, 139 (1990).

3. A. G. MacDiarmid, J. C. Chiang, A. F. Richter, N. L. D. Somasiri, and A. J. Epstein, in Conducting Polymers, L. Alcacer, Ed., Reidel, Dordrecht, Holland, 1987, p. 105.

4. H. Letheby, J. Am. Chem. Soc., 15, 161 (1862).

5. A. G. Green and A. D. Woodhead, J. Chem. Soc. Trans., 97, 2388 (1910); J. Chem. Soc., 101, 1117 (1912).

6. M. Jozefowicz, G. Tyu, G. Belorgy, and R. Buvet, J. Polym. Sci. C, 16, 2943 (1967).

7. M. Angelopoulos, A. Ray, A. G. MacDiarmid, and A. J. Epstein, Synth. Met., 21, 21 (1987).

8. S. K. Manohar, A. G. MacDiarmid, and A. J. Epstein, Synth. Met., 41, 711 (1991).

9. S. K. Manohar, Ph.D. Thesis, University of Pennsylvania, Philadelphia, PA: (1992).

10. Y. Wei, G. W. Jang, C. C. Chan, K. F. Hsueh, R. Hariharan, S. A. Patel, and C. K. Whitecar, J. Phys. Chem., 94, 7716 (1990). 
11. H. Yang and A. J. Bard, J. Electroanal. Chem. 339, 423 (1992).

12. Y. Wei, X. Tang, Y. Sun, and W. W. Focke, J. Polym. Sci. Part A: Polym. Chem., 27, 2385 (1989).

13. D. E. Stilwell and S. M. Park, J. Electrochem. Soc., 2496 (1988).

14. F. L. Klavetter and Y. Cao, Synth. Met., 55-57, 989 (1993).

15. Y. Wei, R. Hariharan and S. A. Patel, Macromolecules, 23, 758 (1990).

16. L. H. C. Mattoso, O. N. Oliveira Jr., R. M. Faria, S. K. Manohar, A. G. MacDiarmid, and A. J. Epstein, Polym. Int., 35, 89 (1994).

17. G. Odian, in Principles of Polymerization, McGrawHill, New York, 1970, p. 652.

18. L. H. C. Mattoso, A. G. MacDiarmid, and A. J. Epstein, Synth. Met., in press.

19. Y. Sun, A. G. MacDiarmid, and A. J. Epstein, J. Chem. Soc. Chem. Commun., 529 (1990).

20. L. H. C. Mattoso, L. O. S. Bulhões, R. M. Faria, and A. G. MacDiarmid, Polymer, 35, 5104 (1994).

21. W. S. Huang, B. D. Humphrey and A. G. MacDiarmid, J. Chem. Soc. Faraday Trans. 1, 82, 2385 (1986).

22. J. G. Masters, Y. Sun and A. G. MacDiarmid, Synth.
Met, 41-43, 715 (1991); M. Wang, J. Polym. Sci. Part A: Polym. Chem., 30, 543 (1992).

23. M. Leclerc, J. Guay, and L. H. Dao, Macromolecules, 22, 649 (1989).

24. J. W. Smith, in The Chemistry of the Amino Group, S. Patai, Ed., Interscience, New York, 1986, p. 161.

25. L. H. Dao, M. Leclerc, J. Guay, and J. W. Chevalier, Synth. Met., 29, E377 (1989).

26. A. Kitani, M. Kaya, J. Yano, K. Yoshikawa, and K. Sasaki, Synth. Met., 18, 31 (1987).

27. M. E. Jozefowicz, A. J. Epstein, J. P. Pouget, J. G. Masters, A. Ray, and A. G. MacDiarmid, Macromolecules, 21, 5863 (1991).

28. A. Ray, Y. Wei, W. W. Focke, G. E. Wnek, and A. G. MacDiarmid, J. Phys. Chem., 93, 495 (1989).

29. J. F. Penneau, M. Lapkowski, and E. M. Genies, New J. Chem. 13, 449 (1989).

30. L. H. C. Mattoso, R. M. Faria, L. O. S. Bulhões, and A. G. MacDiarmid, J. Polym. Sci. Part A: Polym. Chem., 32, 2147 (1994).

Received May 11, 1994

Accepted October 3, 1994 